\title{
Cross-language Neighborhood Effects in Learners Indicative of an Integrated Lexicon
}

\author{
Gabriela Meade $^{1,2,3}$, Katherine J. Midgley ${ }^{2}$, Ton Dijkstra ${ }^{1}$, and Phillip J. Holcomb ${ }^{2}$
}

\begin{abstract}
This study examined how acquisition of novel words from an unknown language (L2) is influenced by their orthographic similarity with existing native language (L1) words in beginning adult learners. Participants were tested in a two-alternative forcedchoice recognition task and a typing production task as they learned to associate $80 \mathrm{~L} 2$ (pseudo)words with pictures depicting their meanings. There was no effect of L1 orthographic neighborhood density on accuracy in the two-alternative forced-choice task, but typing accuracy was higher for L2 words with many L1 neighbors in the earliest stages of learning. ERPs recorded during a language decision task before and after learning also showed differences as a function of L1 neighborhood density. Across ses-
\end{abstract}

\section{INTRODUCTION}

Adults acquiring a second language (L2) must incorporate the new words they learn into the lexical knowledge system they already possess in their native language (L1). Eventually, at high levels of proficiency, words from both languages are thought to form part of an integrated lexicon that is organized according to form similarity (e.g., Dijkstra \& Van Heuven, 2002). Perhaps the most convincing evidence to this effect comes from studies of cross-language neighborhoods, which demonstrate that orthographic and phonological neighbors from both languages influence recognition of a word in proficient bilinguals (e.g., Dirix, Cop, Drieghe, \& Duyck, 2017; Grossi, Savill, Thomas, \& Thierry, 2012; Midgley, Holcomb, Van Heuven, \& Grainger, 2008; Spivey \& Marian, 1999; Van Heuven, Dijkstra, \& Grainger, 1998). At the same time, however, leading models of L2 processing in nonproficient adult learners posit that words from each language are stored in separate lexicons, with cross-language lexical connections limited to translation equivalents (e.g., Grainger, Midgley, \& Holcomb, 2010; Kroll, Van Hell, Tokowicz, \& Green, 2010; Kroll \& Stewart, 1994). Here, we used a cross-language neighborhood manipulation to study the effect of L1 lexical knowledge on the earliest stages of L2 word learning. Using behavioral and ERP measures, we investigated the degree

\footnotetext{
${ }^{1}$ Radboud University, Nijmegen, ${ }^{2}$ San Diego State University,

${ }^{3}$ University of California, San Diego

sions, L2 words with many L1 neighbors elicited slower responses and larger N400s than words with fewer L1 neighbors, suggesting that L1 neighbors continued to influence processing of the L2 words after learning (though to a lesser extent). Finally, ERPs recorded during a typing task after learning also revealed an effect of L1 neighborhood that began about 700 msec after picture onset, suggesting that the cross-language neighborhood effects cannot solely be attributed to bottom-up activation of L1 neighbors. Together, these results demonstrate that strategic associations between novel L2 words and existing L1 neighbors scaffold learning and result in interactions among cross-language neighbors, suggestive of an integrated L1-L2 lexicon. to which L1 orthographic neighborhood density influences acquisition of novel words paired with familiar concepts and, inversely, how learning these words modulates the influence of L1 orthographic neighbors on their processing. Before describing this study, we review the relevant literature on within-language effects of orthographic neighborhood, cross-language effects of neighborhood in proficient bilinguals, and preliminary evidence on how L1 neighbors influence learning, recognition, and production of novel words.

\section{Within-language Effects of Neighborhood on Recognition}

Traditionally, orthographic neighborhood density has been defined as the number of words that are the same length as a given letter string and only differ by one letter (Coltheart's $N$; Coltheart, Davelaar, Jonasson, \& Besner, 1977). For example, lamp has many orthographic neighbors in English (e.g., ramp, camp, lump), but jazz has none. More recently, OLD20 was proposed as a measure of orthographic neighborhood density that better reflects lexical processing by removing the same-length constraint (e.g., Yarkoni, Balota, \& Yap, 2008). OLD20 calculates the mean Levenshtein distance-the number of operations (insertions, deletions, substitutions) required to transform one orthographic string into another-for the 20 most closely resembling words of any length. The fact that the structure of the orthographic neighborhood 
influences processing (see, e.g., Andrews, 1997; Grainger \& Jacobs, 1996, for reviews) is consistent with the architecture of interactive activation models (e.g., McClelland \& Rumelhart, 1981). In this type of model, feedforward activation from representations of individual letters spreads both to the target word and other words containing those letters (i.e., orthographic neighbors). Coactivation of multiple candidate words is then resolved through lateral inhibition until the target word reaches a threshold level of activity and is selected. According to the multiple readout model (Grainger \& Jacobs, 1996), this competition need not be resolved before binary lexical decisions can be made; rather, responses in the lexical decision task (LDT) can be made on the basis of global lexical activation. This response-level account explains why increasing the number of neighbors (and thus the level of global activation) facilitates "word" responses but interferes with "nonword” responses (e.g., Holcomb, Grainger, \& O'Rourke, 2002; Grainger \& Jacobs, 1996).

If behavioral effects of orthographic neighborhood in the LDT are indeed tied to task demands, we might expect similar effects of coactivated neighbors for words and pseudowords earlier in the processing stream. The high temporal resolution of ERPs makes them a wellsuited methodology for addressing this question. The majority of ERP studies investigating neighborhood have focused on the N400 component (e.g., Vergara-Martínez \& Swaab, 2012; Laszlo \& Federmeier, 2009, 2011; Müller, Duñabeitia, \& Carreiras, 2010; Holcomb et al., 2002), a negative-going deflection that peaks about $400 \mathrm{msec}$ after stimulus onset and is associated with lexicosemantic processing (see, e.g., Lau, Phillips, \& Poeppel, 2008; Kutas \& Federmeier, 2000, for reviews). Indeed, irrespective of lexical status, items with many orthographic neighbors elicit larger amplitude N400s than items with fewer neighbors (e.g., Vergara-Martínez \& Swaab, 2012; Müller et al., 2010; Holcomb et al., 2002). In many of these studies, the effect of neighborhood continues past the traditional N400 window onto the subsequent positivity, alternately termed the LPC, P600, or P300 (e.g., Müller et al., 2010; Laszlo \& Federmeier, 2009; Holcomb et al., 2002). This increased negativity is associated with an increase in processing as neighbors activate their own lexicosemantic representations (e.g., Müller et al., 2010; Holcomb et al., 2002).

\section{Cross-language Neighborhood Effects in Proficient Bilinguals}

As mentioned above, cross-language neighborhood density manipulations have been exploited to provide evidence for an integrated lexicon in proficient bilinguals. The number of orthographic and phonological neighbors in the nontarget language appears to influence recognition of both words and pseudowords (e.g., Dirix et al., 2017; Grossi et al., 2012; Midgley et al., 2008; Spivey \& Marian, 1999; Van Heuven et al., 1998). For example,
Van Heuven et al. reported a series of studies with proficient Dutch-English bilinguals in which the number of orthographic neighbors in the nontarget language was manipulated. In an English LDT, bilinguals were slower to respond "word" for real English words with many Dutch neighbors as compared with those with few Dutch neighbors, suggesting that Dutch neighbors had been coactivated and were interfering with processing of the English target word. This is consistent with the responselevel account given in the multiple read-out model, assuming that the global activation parameter is language specific. That is, when the task is to make LDT responses in one language, coactivation of many cross-language neighbors leads to a high level of lexical activity in the nontarget language and interferes with "word" responses.

N400 amplitude has also been found to be sensitive to the neighborhood structure of the nontarget language, but in a way that is more consistent with within-language neighborhood effects (Grossi et al., 2012; Midgley et al., 2008). For example, Midgley et al. found that English words with many orthographic neighbors in French elicited larger amplitude N400s than English words with few orthographic neighbors in French in proficient FrenchEnglish bilinguals, but not in English monolinguals. Both the N400 and behavioral effects of cross-language orthographic neighborhood have been used as evidence for the integrated lexicon implemented in bilingual extensions of interactive activation models (Dijkstra \& Van Heuven, 2002).

\section{Cross-language Neighborhood Effects in Learners?}

Whether this integrated lexicon structure is also present in late adult learners with low levels of L2 proficiency continues to be debated. Some authors have claimed that novel L2 words are integrated directly into the existing lexicons of beginning learners, with lexical connections among neighbors from both languages (e.g., Dijkstra, Haga, Bijsterveld, \& Sprinkhuizen-Kuyper, 2012). Others have argued that novel L2 words are stored independently of the L1 but accessed in parallel, as in the Revised Hierarchical Model (e.g., Kroll et al., 2010; Kroll \& Stewart, 1994). In these models, the only connections at the lexical level are between translation equivalents. Adapting the cross-language neighborhood studies with proficient bilinguals to investigate the dynamics between novel L2 words and their L1 neighbors in learners may be one way to settle this debate.

\section{Recognition of Existing and Novel Words}

There is growing evidence to suggest that acquiring novel words in an L1 context influences recognition of existing neighbors (Bakker, Takashima, Van Hell, Janzen, \& McQueen, 2015; Gaskell \& Dumay, 2003). For example, Bakker and colleagues (2015) taught native Dutch speakers 
different sets of novel words on two consecutive days. The novel words were pseudowords (e.g., pamat) that had been derived from Dutch base words (e.g., patat, meaning "chips") and paired with specific definitions (e.g., "A cat that has stripes and is bluish gray"). In a visual LDT on the second day of learning, responses to the base words of the novel words learned that day were faster than responses to the base words of the unlearned novel words. In contrast, responses to the base words of the novel words learned the previous day were (nonsignificantly) slower (see also, e.g., Gaskell \& Dumay, 2003, for a similar pattern in the auditory modality). These studies have been interpreted to suggest that novel words acquire the ability to interact with existing neighbors upon lexicalization. However, they do not address the extent to which novel L2 words follow a similar trajectory and are also integrated into the L1 lexicon.

Another approach to investigating the relationship between novel words and their existing neighbors is to track recognition of the novel words themselves as a function of L1 neighborhood density. In the only study to our knowledge that explicitly compared recognition of novel words with many versus few L1 neighbors, Magnuson, Tanenhaus, Aslin, and Dahan (2003) found no effect of phonological neighborhood density. The novel words in this study consisted of pseudowords (e.g., sheed, yarp) that were formed by changing the final consonant of existing L1 words (e.g., sheep, yarm) with high- or low-density phonological neighborhoods. Participants learned to associate 20 such words, presented auditorily, with geometric shapes and were tested in a visual world paradigm. There was little effect of phonological neighborhood on eye movements during processing of the novel words, leading the authors to suggest that "an artificial lexicon of words that conform to native phonotactics might be considered functionally isolated from a participant's native lexicon" (p. 223). In other words, contrary to the studies on recognition of existing words, these results suggest that novel words do not interact with existing neighbors. Interpreted within the context of L2 models, this pattern would appear to be more consistent with the language-specific lexicons posited in the Revised Hierarchical Model. However, it is not clear whether an L2 framework is appropriate for these novel word learning studies, as the focus was never on cross-language dynamics and the learning context did not approximate a typical L2 learning situation (e.g., the meanings associated with the words were either too abstract or too specific).

ERP evidence related to the effect of L1 neighborhood on L2 processing in learners is also lacking. However, N400 amplitude does appear to be sensitive to L2 word learning, perhaps even more so than behavioral measures (e.g., Pu, Holcomb, \& Midgley, 2016; McLaughlin, Osterhout, \& Kim, 2004). Moreover, recent ERP evidence from a study comparing L1 and L2 processing in relatively low-proficiency classroom learners was interpreted to support separate language-specific lexicons. In a semantic categorization task, Midgley, Holcomb, and Grainger (2009) found that the N400s elicited by L2 words were smaller than the N400s elicited by L1 words in lowproficiency English-French and French-English bilinguals. The authors interpreted this effect as evidence that distinct mechanisms underlie word recognition at different levels of proficiency. They suggested that the smaller amplitude N400 was in part due to a sparser neighborhood structure for L2 words because of the relatively smaller L2 vocabulary. The sparse L2 neighborhoods could indeed result from language-specific lexicons, such that L2 words are only neighbored by the limited set of other known L2 words. A potential alternative, however, is that words from both languages formed part of an integrated lexicon, but that L2 words were distinct enough in form from the large majority of L1 words (see, e.g., Vitevitch, 2012) and therefore had smaller neighborhoods. Thus, this study does not decisively resolve whether L1 and L2 words are stored together or separately at low levels of proficiency.

\section{Production of Novel Words}

Contrary to the recognition studies discussed above, L1 phonological neighborhood density has been found to have a facilitatory effect on production of novel words. For example, performance in a picture-naming task involving novel (pseudo)words learned with unfamiliar pictures was positively correlated with L1 phonological neighborhood density (Storkel, Armbrüster, \& Hogan, 2006). This high neighborhood density advantage in production is consistent with the literature on processing of existing words. In general, production is faster and more accurate for words with many within-language phonological neighbors (e.g., Vitevitch, 2002), an effect attributed to pronunciation-specific processes (e.g., Carreiras, Perea, \& Grainger, 1997). Similarly, in the study by Storkel and colleagues, novel words with many L1 neighbors may have been produced more accurately because their motor codes were more readily available via analogy with a greater number of existing neighbors. It is therefore difficult to determine on the basis of these behavioral results whether the facilitation resulted from the coactivation of $\mathrm{L} 1$ neighbors at a lexical level (i.e., was evidence of an integrated lexicon) or occurred at a later language nonspecific articulatory stage.

ERP studies of word production have only recently begun to emerge (see Ganushchak, Christoffels, \& Schiller, 2011, for a review) and none, to our knowledge, have investigated effects of orthographic or phonological neighborhood density, even within one language. Most relevant for the present focus on orthographic word forms is a study in which participants typed the names of pictures in their L1 (Baus, Strijkers, \& Costa, 2013). Half of the picture names were high-frequency words, and the other half were low-frequency words. ERPs in response to the two types of words began to diverge about $330 \mathrm{msec}$ after 
picture onset, suggesting that ERPs are sensitive to lexical characteristics during a typing task. Extending these results to include ERP effects of L1 neighborhood density during production of L2 words would establish a lexical locus of the interaction observed in behavioral studies between novel words and their L1 neighbors, consistent with an integrated L1-L2 lexical structure.

\section{The Present Study}

Understanding how the L1 neighborhood influences acquisition and processing of L2 words is one approach to settling the debate between separate and integrated lexicons in learners. Nevertheless, as reviewed above, research on this topic is limited to a few behavioral studies, most of which involve acquisition of pseudowords and a learning task that does not simulate L2 learning. Potentially consistent with the separate lexical system hypothesis is evidence from recognition studies suggesting that novel words form an encapsulated system independent from the influence of existing neighbors (e.g., Magnuson et al., 2003). Potentially consistent with an integrated lexical system is evidence from production studies suggesting an advantage for novel words with many L1 neighbors (e.g., Storkel et al., 2006). Here, we aimed to clarify the role of L1 orthographic neighborhood on recognition of novel words before and after learning, as measured by ERPs and behavioral responses in a language decision task (e.g., Casaponsa, Carreiras, \& Duñabeitia, 2014; Dijkstra, Miwa, Brummelhuis, Sappelli, \& Baayen, 2010; Vaid \& Frenck-Mestre, 2002) and a picture typing task at posttest. The language decision task was a lexicosemantic task that was accessible to learners before and after learning. This enabled us to measure changes in the influence of L1 neighbors on processing of the L2 words across sessions while minimizing differential effects of task. The typing paradigm was included to further probe effects of orthographic neighborhood. ${ }^{1}$ For one, the task demands were such that only L2 knowledge was relevant (rather than the mixed language context of the language decision task), making it a more stringent test of crosslanguage neighbor coactivation. For another, the L2 words were never explicitly presented in the typing task. This makes it difficult to attribute potential cross-language neighborhood effects to feedforward activation from the letters on the screen to lexical representations in separate lexicons (cf. Kroll et al., 2010). Rather, L1 neighbors should only be activated in this case if they are richly interconnected at the lexical level to form-related L2 items, as in an integrated lexicon. Together, finding effects of L1 orthographic neighborhood on recognition and production of novel L2 words would support an integrated L1-L2 lexical structure, even in beginning learners.

In the language decision task, we predicted that L2 words with many L1 orthographic neighbors would elicit slower and less accurate responses and larger amplitude N400s than those with fewer orthographic neighbors, consistent with previous LDT studies (e.g., Holcomb et al., 2002). We expected this effect to decrease in size from pretest to posttest as a result of lateral inhibition. At pretest, there are no lexical representations for the L2 words; however, these representations presumably develop with learning and acquire the ability to inhibit their L1 neighbors, decreasing (but not eliminating) their influence on L2 processing. An online effect of L1 orthographic neighborhood in the final ERP typing task would provide evidence of an integrated lexicon, in which activation spreads from the lexical representation of the L2 target word to its L1 neighbors. Following the L1 frequency typing results reported by Baus et al. (2013), we expected that L2 words with many L1 orthographic neighbors would elicit a larger negativity than those with only a few L1 orthographic neighbors beginning at about $330 \mathrm{msec}$ after picture onset. In contrast, if the lexicons are functionally separate and the only connections at the lexical level are between translation equivalents, there should be no evidence of L1 neighbor coactivation at posttest in either the language decision task or the typing task.

\section{METHODS \\ Participants}

Participants included 20 native English speakers (15 women; mean age $=22.2$ years, $S D=3.0$ years) who were not fluent in any other language and had not been exposed to another language before the age of 6 years. By self-report, all participants were right-handed, had normal or corrected-to-normal vision, had no history of neurological dysfunction or language or reading disorders, and were not taking any medications that would affect brain function. Participants were volunteers who received course credit and/or monetary compensation for their time. Informed consent was obtained from all participants in accordance with the institutional review board at San Diego State University. Three additional participants were excluded from analyses because of high artifact rejection rates or poor learning.

\section{Stimuli}

Stimuli included 80 real English nouns and 80 pseudowords from the ARC Nonword Database (Rastle, Harrington, \& Coltheart, 2002) - referred to throughout as L2 words - that were four to five letters in length. Half of the stimuli in each language condition belonged to a low-density English orthographic neighborhood (OLD20 $\geq 1.85$ ) and the other half belonged to a high-density English orthographic neighborhood (OLD20 $\leq 1.75)$. Low-density neighborhood L2 words had a significantly larger English OLD20 (mean = $2.18, S D=0.30)$ than high-density neighborhood L2 words (mean $=1.57, S D=0.15), t(78)=11.22, p<.001$. Similarly, low-density neighborhood English words had a significantly larger OLD20 (mean $=2.09, S D=0.29)$ than 
high-density neighborhood English words (mean $=1.57$, $S D=0.12), t(78)=10.51, p<.001 .^{2}$ These differences are comparable to previous investigations of orthographic neighborhood density that have used OLD20. For example, Vergara-Martínez and Swaab (2012) used real Englishwords ranging from four to six letters in length and reported mean OLD20 values of 1.515 in their highdensity neighborhood condition and 2.105 in their lowdensity neighborhood condition. None of the stimuli were orthographic neighbors with other words included in the paradigm.

Other nuisance variables known to affect N400 amplitude, including sublexical regularity, letter length, and frequency, were controlled across lists in an attempt to isolate the effect of orthographic neighborhood (see Table 1). For example, sublexical regularity is known to correlate with neighborhood density in English (e.g., Vitevitch, Luce, Pisoni, \& Auer, 1999), thus constrained and unconstrained unigram and bigram frequencies were controlled across lists (all $p s>.05$ ). These metrics were extracted from the MCWord database (Medler \& Binder, 2005).

During training, each novel L2 word was presented with a picture that depicted a familiar object. Thus, like the English words, all L2 words were assigned a singular noun meaning. Two lists of 40 pictures with naming agreement of $85 \%$ or higher (mean $=97 \%$; Bates et al., 2003) were created. Each picture from these lists was presented in association with an L2 word from a high-density neighborhood for half of the participants and in association with an L2 word from a low-density neighborhood for the other half of the participants. This minimized any confounding effects of semantics or other properties of the pictures in posttest neighborhood analyses of interest. Furthermore, concreteness (Brysbaert, Warriner, \& Kuperman, 2014) and frequency (Medler \& Binder, 2005) were controlled between the English names of the pictures and the English words included in the language decision task (all $p \mathrm{~s}>.2$ ) to minimize effects of semantics across lists.

\section{Procedure}

\section{ERP Sessions}

Two ERP sessions took place 3 days apart. Each session began with a language decision task consisting of 160 tri- als, half of which were English words. Stimuli were presented in lowercase Arial font, such that the widest stimulus subtended a horizontal visual angle of $2^{\circ}$. Each trial began with a purple fixation cross that remained on the screen for $1500 \mathrm{msec}$ and was followed by a white fixation for $900 \mathrm{msec}$ and a blank screen for $500 \mathrm{msec}$. The word then appeared on the screen for $300 \mathrm{msec}$. After word offset, the screen was blank again until the subsequent trial began 700 msec after the button press response. Participants were given short breaks after every 20 trials and a longer break halfway through the experiment. They were asked to blink only during these breaks or during the purple fixation between trials. Participants were asked to press one button on a videogame response box for English words and another button for words from the language they would be learning/had learned as quickly and accurately as possible. English response hand was counterbalanced across participants.

Words were presented in one of two possible pseudorandom orders, such that participants saw different lists at pretest and posttest; list order was counterbalanced across participants. No more than three consecutive trials came from the same language condition or the same neighborhood condition. Orthographic overlap between consecutive words was minimized, and words that were semantically related (e.g., crib and baby) were separated by at least 10 trials. Each language decision task began with one of two practice lists. Each practice list contained the same 12 stimuli, six of which were real English words, arranged into two pseudorandom orders. None of the items used in the practice were included in the experimental lists.

During the posttest, participants also took part in a picture typing task. ${ }^{3}$ In this task, the same pictures that were used during training (see below) were presented for $800 \mathrm{msec}$, subtending a visual angle of $3.3^{\circ}$ in each direction. Participants were asked to look down at the backlit keyboard on their laps after the picture was replaced by a purple fixation cross. They then typed the L2 word associated with that picture and pressed enter. Two thousand milliseconds after they pressed enter, a white fixation cross appeared on the screen, signaling the beginning of the next trial. Participants were asked to keep their eyes at the center of the screen and to try not to blink

Table 1. Stimulus Characteristics, Mean $(S D)$

\begin{tabular}{|c|c|c|c|c|c|c|c|}
\hline & $O L D 20$ & $N$ & $\begin{array}{c}\text { Constrained } \\
\text { Unigram Frequency }\end{array}$ & $\begin{array}{c}\text { Unconstrained } \\
\text { Unigram Frequency }\end{array}$ & $\begin{array}{c}\text { Constrained } \\
\text { Bigram Frequency }\end{array}$ & $\begin{array}{l}\text { Unconstrained } \\
\text { Bigram Frequency }\end{array}$ & Frequency \\
\hline L2 HD & $1.57(0.15)$ & $8.05(3.27)$ & $10,171(4270)$ & $235,410(59,714)$ & $1036(658)$ & $17,640(12,760)$ & - \\
\hline L2 LD & $2.18(0.30)$ & $0.65(0.89)$ & 9166 (3129) & $219,063(51,789)$ & 864 (829) & 14,017 (9042) & - \\
\hline L1 HD & $1.57(0.12)$ & $7.40(2.54)$ & 9297 (2822) & $227,330(54,827)$ & $839(476)$ & 15,241 (8999) & $38.45(54.74)$ \\
\hline L1 LD & $2.09(0.29)$ & $0.75(0.90)$ & 8489 (3919) & $235,093(62,262)$ & $756(1002)$ & 15,768 (11691) & $36.56(71.08)$ \\
\hline
\end{tabular}

L2 = pseudowords learned during training; HD = high-density L1 neighborhood; LD = low-density L1 neighborhood. All metrics except OLD20 extracted from the MCWord database (Medler \& Binder, 2005). 
while the white fixation cross and picture were on the screen. A practice session included the pictures paired during training with the six L2 words from the language decision practice.

\section{Training}

In between the ERP sessions, participants took part in three consecutive days of word learning using QRTEngine (Barnhoon, Haasnoot, Bocanegra, \& van Steenbergen, 2015). The first part of the training (see Table 2) took place at the lab following the first ERP session. To begin, participants saw each of the L2 words presented with a picture that depicted the meaning of the word. This task was interwoven with a two-alternative forced-choice (2AFC) task in which a picture was presented above two L2 words (the corresponding word and a filler; see Figure 1A). Fillers were randomly chosen from the other L2 words, such that the same filler never appeared with any given target word more than once. Feedback was provided after each trial. After trials that the participant answered correctly, the corresponding L2 word appeared in green; after trials that the participant answered incorrectly, the correct L2 word appeared in red (see Figure 1B). L2 words were introduced and tested like this in blocks of about 10 items until all 86 words and pictures had been presented (40 low-density L2 words, 40 high-density L2 words, and 6 practice items). After this, participants saw all 80 pictures again in the 2AFC paradigm and typing task. In the latter, participants saw each picture and were asked to type its L2 name. The first and last letters of the correct L2 word and underscores for the intervening letters were provided as a cue (see Figure 1C). If they answered correctly, they advanced to the next trial. If they answered incorrectly, a screen identical to the feedback for incorrect $2 \mathrm{AFC}$ trials was presented before a second attempt.

The second and third days of training were completed online. Participants were instructed to complete the training in one sitting and in a quiet place where they would not be distracted. Compliance was ensured by monitoring the amount of time participants spent on each

Table 2. Training Paradigm

\begin{tabular}{llll}
\hline Day 1 & Day 2 & Day 3 & \multicolumn{1}{c}{ Day 4 } \\
\hline Language decision & 2AFC & 2AFC & Language decision \\
Paired associate/2AFC & Typing $^{\mathrm{a}}$ & Typing $^{\mathrm{b}}$ & L2-L1 priming \\
2AFC & 2AFC & 2AFC & Typing \\
Typing $^{\mathrm{a}}$ & Typing $^{\mathrm{b}}$ & Typing & \\
\hline
\end{tabular}

Red print indicates that EEG was recorded.

${ }^{a}$ First and last letters provided as a cue.

${ }^{\mathrm{b}}$ First letter provided as a cue.

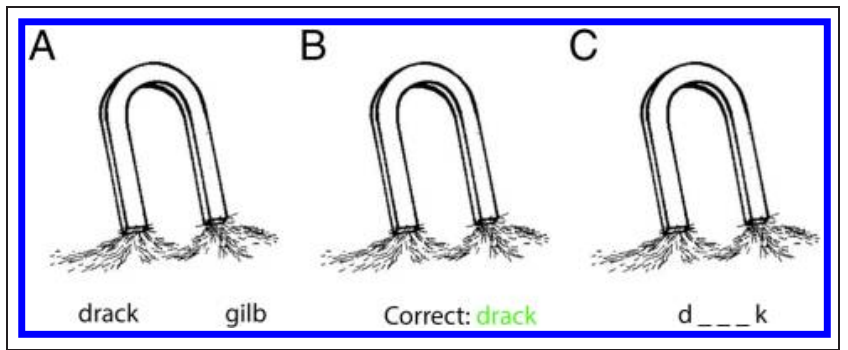

Figure 1. Training paradigm. (A) In the $2 \mathrm{AFC}$ task, participants saw the target word (e.g., drack) and another L2 word (e.g., gilb) and were asked to choose the correct name of the picture. (B) Feedback in the 2AFC was provided on every trial. The picture was displayed with the correct L2 word, in green if it had been chosen correctly and in red if the incorrect word had been chosen. (C) In the typing task, participants saw the picture and had to type the correct word. In the early sessions, the first and last letters were provided as cues, as shown here (see Table 2)

trial. The second day of training consisted of a 2AFC task, followed by a typing task with the first and last letter cues, another 2AFC task, and a typing task with only the first letter as a cue. The third day had a similar structure as the second day; however, in the first typing task, only the first letter was provided as a cue, and in the final typing task, no hints were provided. Across the 3 days of learning and the various tasks, participants were exposed to each of the novel words a total of 12 times.

Across all training tasks, order of presentation was pseudorandomized such that no more than three consecutive trials belonged to either neighborhood condition. In addition, in the $2 \mathrm{AFC}$, the correct response did not appear on the same side of the screen for more than three consecutive trials.

\section{EEG Recording and Analysis}

Participants were fitted with an elastic cap (Electro-Cap, Eaton, OH) with 29 electrodes (see Figure 2). An electrode placed on the left mastoid was used as a reference during recording and for subsequent analyses. An electrode located below the left eye was used to identify blink artifacts in conjunction with recordings from FP1; an electrode on the outer canthus of the right eye was used to identify artifacts due to horizontal eye movements. Using saline gel (Electro-Gel, ECI, Eaton, OH), mastoid and scalp electrode impedances were maintained below $2.5 \mathrm{k} \Omega$, and eye electrode impedances below $5 \mathrm{k} \Omega$. EEG was amplified with SynAmpsRT amplifiers (Neuroscan-Compumedics, Charlotte, NC) with a band pass of DC to $100 \mathrm{~Hz}$ and was sampled continuously at $500 \mathrm{~Hz}$.

ERPs in the language decision task were time-locked to the onset of each word. Offline, separate ERPs for each condition were averaged for each subject at each electrode site over a 1100-msec epoch, using a 100-msec prestimulus onset baseline, and low-pass filtered at $15 \mathrm{~Hz}$. Trials contaminated by eye movements or drift were excluded (mean of $3 \%$ trials rejected from pretest, $2 \%$ from posttest), as 


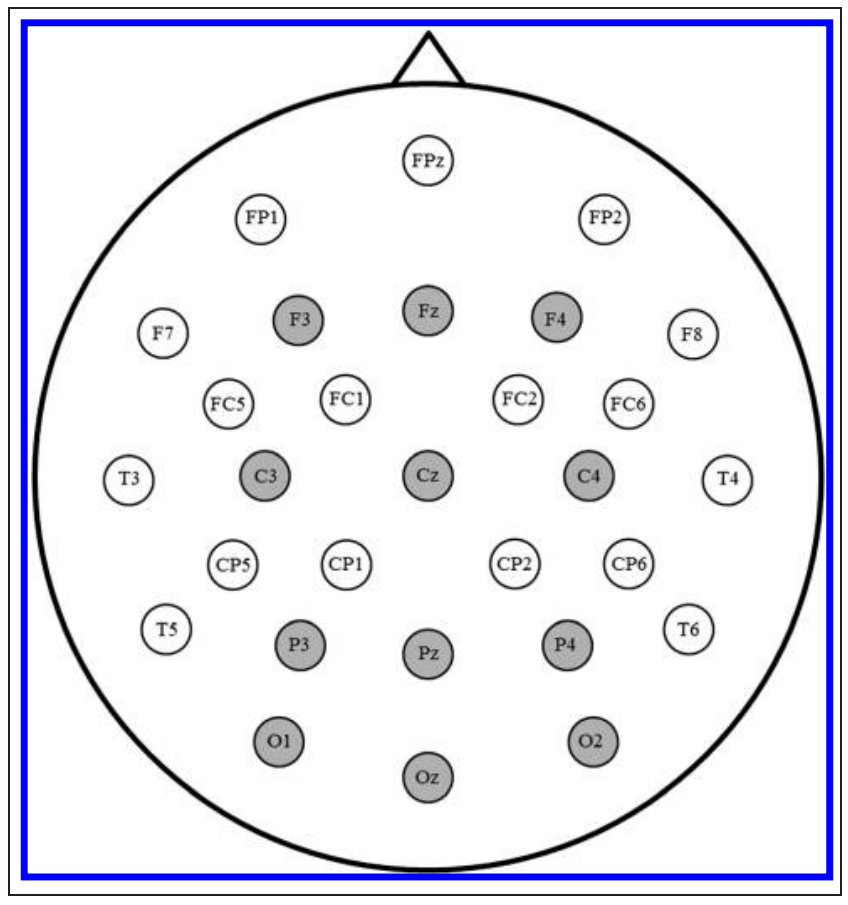

Figure 2. Electrode montage. Sites indicated in gray were included in analyses.

were trials with incorrect responses (mean of $4 \%$ of trials at pretest, $2 \%$ at posttest). In the final analyses, of 40 total possible trials, there were an average of $36.4(S D=4.1)$ in the pretest high-density condition, $38.0(S D=1.7)$ in the pretest low-density condition, $38.0(S D=1.4)$ in the posttest high-density condition, and $38.8(S D=1.2)$ in the posttest low-density condition. Analyses focused on L2 words at the 12 representative electrode sites indicated in Figure 2. On the basis of visual inspection of the grand-averaged waveforms and difference waves, mean amplitude was calculated for two consecutive time windows: 300-450 msec and 450-600 msec. Although these two time windows were chosen to capture the N400 and the onset of the subsequent positivity, respectively, difference waves suggested that the same underlying effect persisted throughout both time windows. For each time window, omnibus ANOVAs with factors session (pretest, posttest), neighborhood (high, low), laterality (left, right, midline), and anterior/ posterior (frontal, central, parietal, occipital) were conducted. Greenhouse-Geisser correction was applied for all within-subject measures with more than one numerator degrees of freedom. Partial eta squared $\left(\eta_{\mathrm{p}}^{2}\right)$ is reported as a measure of effect size.

Preprocessing in the typing task was identical, except that ERPs were time-locked to picture onset and a 100-msec poststimulus onset baseline was used to minimize differential influence of early components. Across participants, $5 \%$ of trials were rejected for artifacts and $4 \%$ were rejected for incorrect responses. In the final analyses, an average of 36.6 trials $(S D=3.2$ ) out of 40 were included in the highdensity condition and an average of 35.4 trials $(S D=3.8)$ were included in the low-density condition. Visual inspection and a time-course analysis indicated that the effect of L1 neighborhood was significant between about 700 and 950 msec. Thus, an ANOVA with factors neighborhood (high, low), laterality (left, right, midline), and anterior/ posterior (frontal, central, parietal, occipital) was conducted on the mean amplitude within this time window at the 12 sites indicated in Figure 2.

\section{RESULTS}

\section{Training}

The effect of L1 orthographic neighborhood on accuracy was analyzed using separate repeated-measures ANOVAs for the 2AFC and typing tasks with factors Neighborhood (high, low) and Session. There were six levels of Session for the 2AFC (two on each day) and five levels of Session for the typing task (one on Day 1, two each on Days 2 and 3; refer to Table 2). A simple main effect of Session indicated that performance in the 2AFC increased over time, $F(5,95)=7.2, p=.005, \eta_{\mathrm{p}}^{2}=.27$ (see Figure $3 \mathrm{~A}$ ). In contrast, there was no main effect of Neighborhood, $F(1,19)=0.96, p=.34, \eta_{\mathrm{p}}^{2}=.05$, or interaction between Neighborhood and Session, $F(5,95)=1.09, p=.37$,
Figure 3. Training accuracy. (A) Performance in the $2 \mathrm{AFC}$ task over learning sessions as a function of L1 neighborhood density. Accuracy increased over sessions but was similar for high-density (solid) and low-density (dotted) L2 words. Bars indicate standard error. (B) Performance in the typing task over sessions. Accuracy increased over sessions and performance was significantly better for high-density L2 words (solid) than for low-density L2 words (dotted) during the first three sessions. Bars indicate standard error.

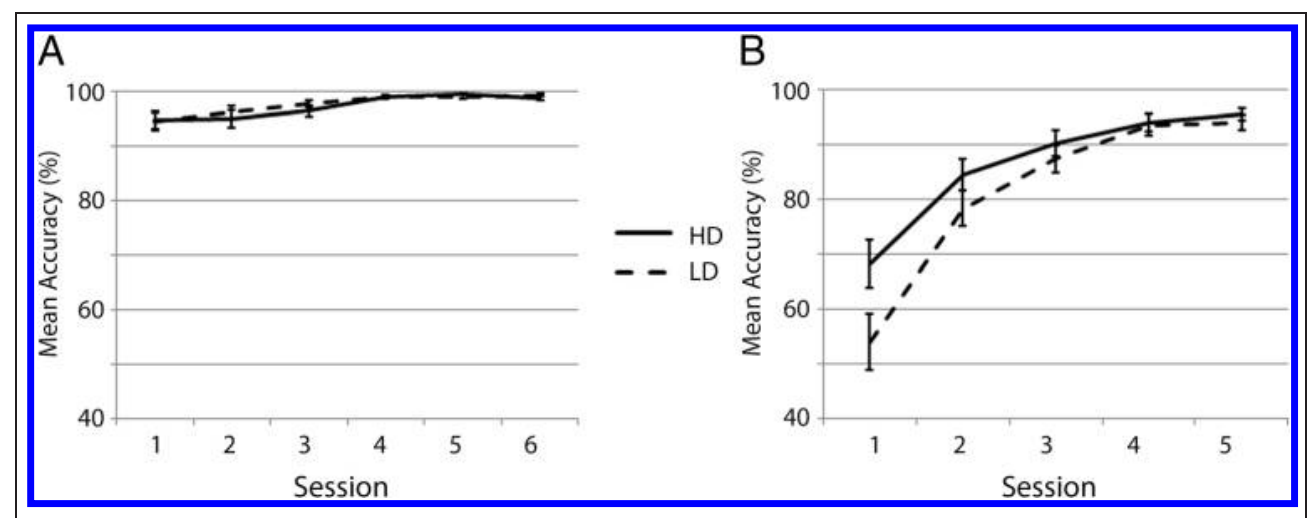


$\eta_{\mathrm{p}}^{2}=.05$, indicating that recognition accuracy was similar for L2 words from high- and low-density L1 neighborhoods in the 2AFC. Accuracy in the typing task also increased across sessions, $F(4,76)=64.77, p<.001, \eta_{\mathrm{p}}^{2}=$ .77 (see Figure $3 \mathrm{~B}$ ). In contrast to the 2AFC, typing performance was better for words from high-density L1 neighborhoods as compared with words from low-density L1 neighborhoods, $F(1,19)=25.3, p<.001, \eta_{\mathrm{p}}^{2}=.57$, particularly in the early sessions, Neighborhood $\times$ Session, $F(4,76)=17.89, p<.001, \eta_{\mathrm{p}}^{2}=.48$. In follow-up pairedsamples $t$ tests by session, the effect of Neighborhood was significant at the first, $t(19)=5.65, p<.001, \eta_{\mathrm{p}}^{2}=$ .63 , second, $t(19)=3.84, p=.001, \eta_{\mathrm{p}}^{2}=.44$, and third, $t(19)=3.17, p=.005, \eta_{\mathrm{p}}^{2}=.34$, sessions, but not thereafter (both $p s>.12$ ). Thus, L2 words with many L1 neighbors were initially at an advantage in the typing task, but that effect disappeared once participants reached ceiling levels of accuracy for both conditions in later sessions.

\section{Language Decision ERP Task}

\section{Behavior}

The effects of L1 orthographic neighborhood on accuracy and RTs for L2 words in the language decision task were analyzed using $2 \times 2$ repeated-measures ANOVAs with factors Session (pretest, posttest) and Neighborhood (high, low). RTs faster than $200 \mathrm{msec}$ or slower than 2000 msec were discarded. L2 words with few L1 orthographic neighbors (mean $=699 \mathrm{msec}$ ) elicited faster responses than L2 words with many L1 orthographic neighbors $($ mean $=772 \mathrm{msec}), F(1,19)=58.06, p<$ $.001, \eta_{\mathrm{p}}^{2}=.75$ (see Figure 4A). This effect decreased with learning, Neighborhood $\times$ Session, $F(1,19)=4.26$, $p=.053, \eta_{\mathrm{p}}^{2}=.183$, but was evident at both pretest, $F(1,19)=115.51, p<.001, \eta_{\mathrm{p}}^{2}=.86$, and posttest, $F(1,19)=13.27, p=.002, \eta_{\mathrm{p}}^{2}=.41 . \mathrm{L} 2$ words with few L1 orthographic neighbors (mean $=39.58$ out of 40 , or $99 \%$ ) were also categorized more accurately than L2 words with many L1 orthographic neighbors (mean = 38.15 out of 40 , or $95 \%), F(1,19)=14.14, p<.001, \eta_{p}^{2}=$ .43 (see Figure 4B). Thus, consistent with previous pseudoword and cross-language neighborhood findings, L2 words with few L1 orthographic neighbors were identified faster and more accurately than L2 words with many L1 orthographic neighbors.

\section{0-450 msec}

There was a main effect of Session such that the N400 in response to L2 words decreased from pretest (mean $=$ $0.60 \mu \mathrm{V})$ to posttest $(2.30 \mu \mathrm{V}), F(1,19)=6.13, p=.023$, $\eta_{\mathrm{p}}^{2}=.24$ (see Figure 5). A main effect of Neighborhood indicated that L2 words with many L1 orthographic neighbors (mean $=0.72 \mu \mathrm{V}$ ) elicited a larger amplitude N400 than L2 words with few L1 orthographic neighbors (mean = $2.18 \mu \mathrm{V}), F(1,19)=22.83, p<.001, \eta_{\mathrm{p}}^{2}=.54$ (see Fig-

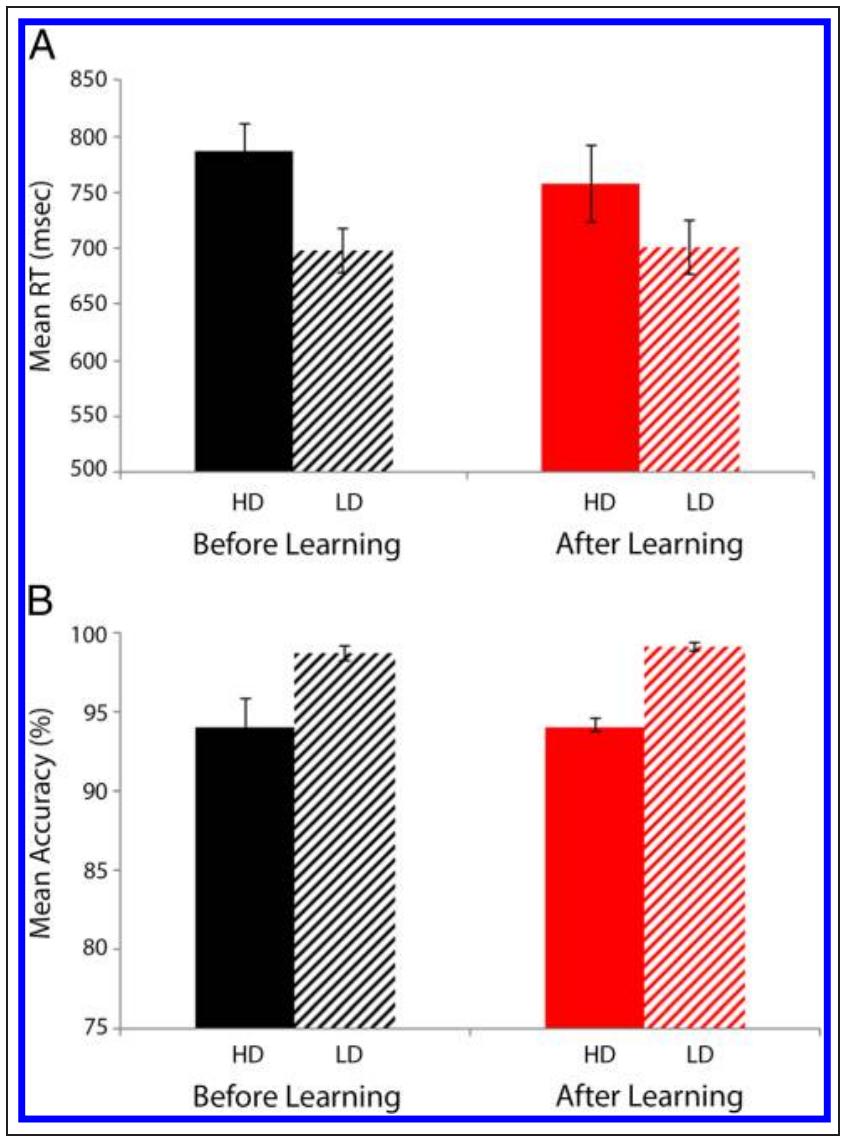

Figure 4. Language decision: Behavioral responses. (A) Mean RTs for L2 words in the language decision task. The effect of neighborhood, such that high-density neighborhood L2 words (solid) elicited slower responses than low-density neighborhood L2 words (striped), was significant in both sessions but stronger before learning. Bars indicate standard error. (B) Mean accuracy for L2 words in the language decision task. Accuracy was lower overall for L2 words from high-density neighborhoods (solid) than for L2 words from low-density neighborhoods (striped). Bars indicate standard error.

ures 6 and 7). This effect was strongest over central midline and right hemisphere sites, Neighborhood $\times$ Laterality, $F(2,38)=7.37, p=.004, \eta_{\mathrm{p}}^{2}=.28$, Neighborhood $\times$ Laterality $\times$ Anterior/Posterior, $F(6,114)=3.53, p=$ $.026, \eta_{\mathrm{p}}^{2}=.16$. There was not, however, a significant interaction between Session and Neighborhood in this epoch, $F(1,19)=0.25, p=.62, \eta_{\mathrm{p}}^{2}=.01$.

\section{0-600 msec}

L2 words at pretest continued to elicit a larger negativity than L2 words at posttest in this time window, especially over left hemisphere and posterior sites, Session $\times$ Laterality, $F(2,38)=7.67, p=.002, \eta_{\mathrm{p}}^{2}=.29$, Session $\times$ Anterior $/$ Posterior, $F(3,57)=4.23, p=.033, \eta_{\mathrm{p}}^{2}=.18($ refer to Figure $5 \mathrm{~B}$ ). Words from high-density orthographic neighborhoods (mean $=3.92 \mu \mathrm{V}$ ) also continued to elicit a greater negativity (or smaller positivity) than words from lowdensity orthographic neighborhoods (mean $=6.25 \mu \mathrm{V}$ ), 
$F(1,19)=27.64, p<.001, \eta_{\mathrm{p}}^{2}=.59$ (refer to Figures 6 and 7), but differed between sessions, Neighborhood $\times$ Session, $F(1,19)=12.06, p=.002, \eta_{\mathrm{p}}^{2}=.389$. Follow-up analyses by session indicated that the effect of Neighborhood held at pretest and tended to be strongest over central and parietal midline sites, Neighborhood, $F(1,19)=53.32, p<.001, \eta_{\mathrm{p}}^{2}=.74$, Neighborhood $\times$ Laterality $\times$ Anterior/Posterior, $F(6,114)=2.86, p=$ $.034, \eta_{\mathrm{p}}^{2}=.13$. A similar, but comparatively smaller, effect of orthographic neighborhood also approached significance at posttest, $F(1,19)=4.2, p=.055, \eta_{\mathrm{p}}^{2}=.18$.

\section{Typing ERP Task}

Consistent with the typing sessions on the last day of training, accuracy in the ERP typing task did not differ between low-density (mean $=38.0$ out of 40 , or $95 \%$ ) and high-density $($ mean $=38.4$ out of 40 , or $96 \%$ ) neighborhood words, $t(19)=1, p=.33, \eta_{\mathrm{p}}^{2}=.05$. However, the timecourse analysis yielded an effect of L1 orthographic neighborhood density in the ERP waveform (see Figure 8A) that began around 700 msec. A main effect of Neighborhood on mean amplitude between 700 and 950 msec confirmed that picture names with many L1 orthographic neighbors elicited a greater negativity than picture names with fewer L1 orthographic neighbors, $F(1,19)=21.61, p<.001$, $\eta_{\mathrm{p}}^{2}=.53$ (see Figure $8 \mathrm{~B}$ and $\left.\mathrm{C}\right){ }^{4}$

\section{DISCUSSION}

In the first ERP study to investigate cross-language effects of orthographic neighborhood in low-proficiency learners, we found converging evidence for an integrated L1-L2 lexicon. In the early stages of learning, accuracy was higher for L2 words with many L1 orthographic neighbors in the typing task, but not the $2 \mathrm{AFC}$ task. ERP data recorded to
Figure 5. Language decision: Effect of learning. Grand averaged ERP waveforms elicited by all $\mathrm{L} 2$ words before learning (black) and after learning (red). Each vertical tick marks $100 \mathrm{msec}$, and negative is plotted up. The calibration bar marks $2 \mu \mathrm{V}$. (B) Scalp voltage maps showing the effect of learning (pretest-posttest) for each of the analyzed time windows.

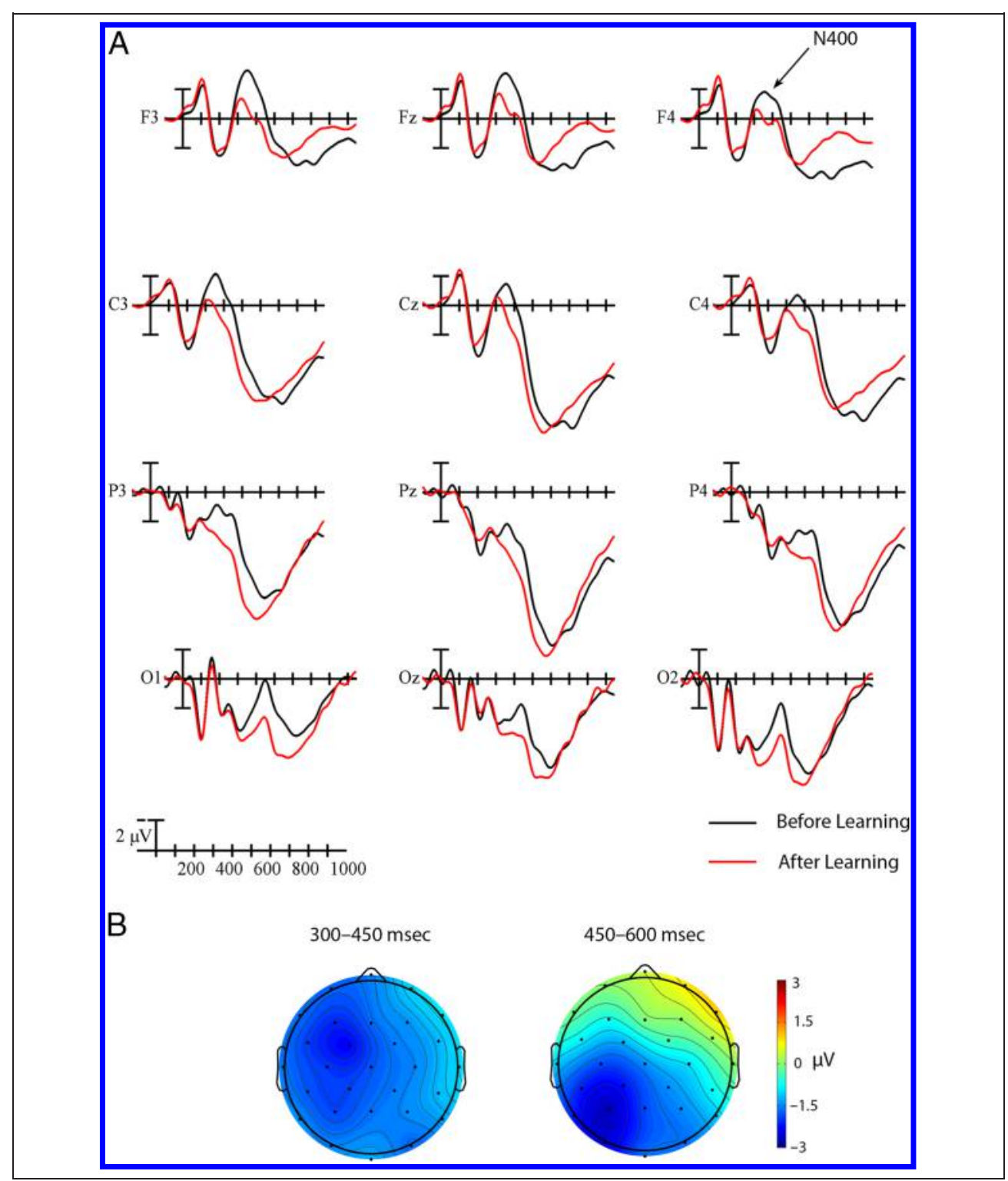




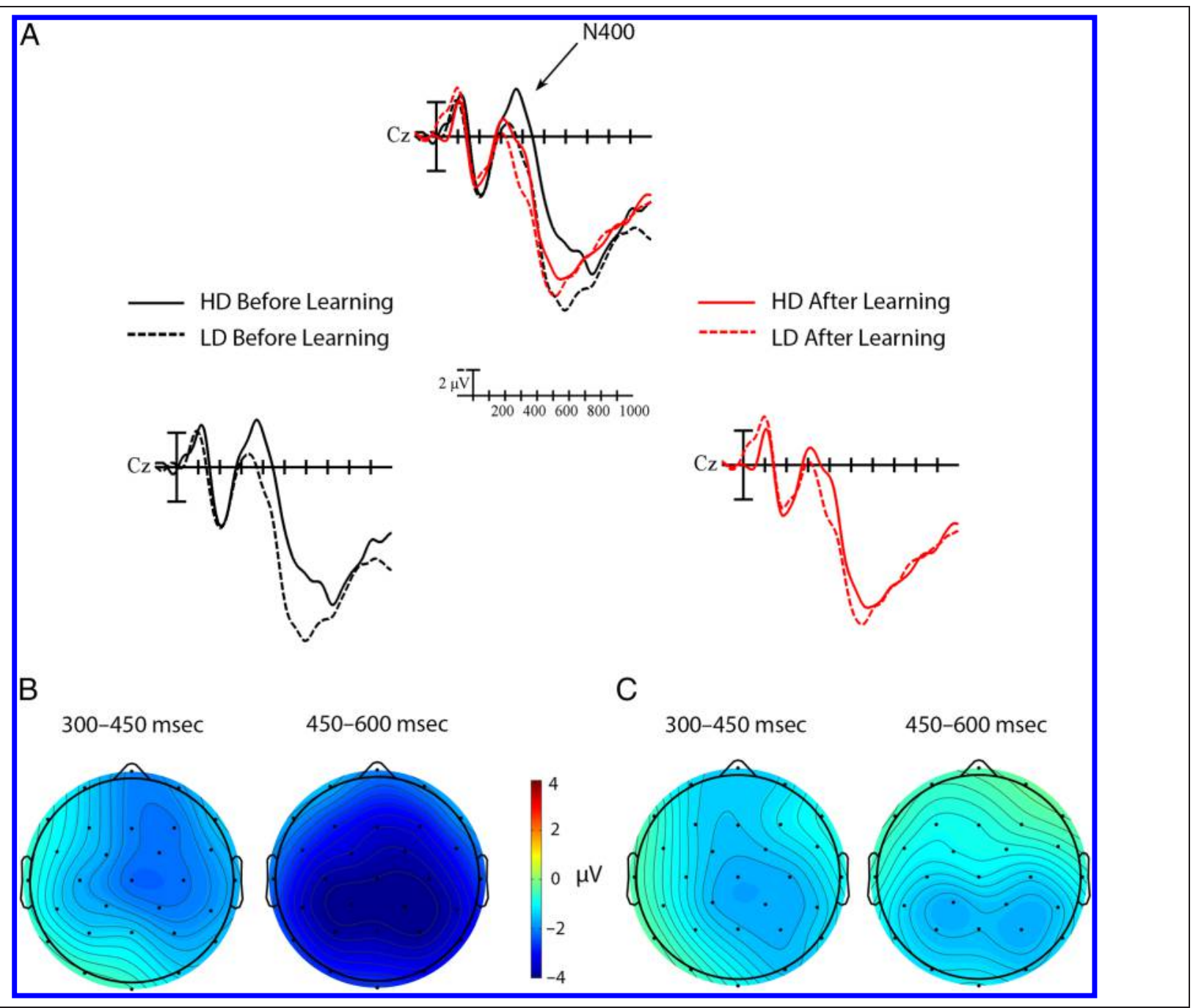

Figure 6. Language decision: Effect of L1 neighborhood. (A) Grand averaged ERP waveforms elicited by L2 words belonging to high-density (solid) or low-density (dotted) L1 neighborhoods at representative site Cz, both before (black) and after (red) learning. Each vertical tick marks $100 \mathrm{msec}$, and negative is plotted up. The calibration bar marks $2 \mu \mathrm{V}$. (B) Scalp voltage maps showing the effect of L1 neighborhood density (high-low) for each of the analyzed time windows before learning. (C) Scalp voltage maps showing the effect of neighborhood density (high-low) for each of the analyzed time windows after learning.

these words and the pictures representing their meanings were indicative of an integrated L1-L2 lexicon. In the language decision task, L2 words with many L1 neighbors elicited a larger amplitude N400 and slower "other language" responses than those from a low-density $\mathrm{L} 1$ neighborhood and more so at pretest than at posttest. We attribute this decrease in the effect of L1 orthographic neighborhood to the formation of lexical representations for the L2 words over the course of learning; at posttest, the newly formed lexical representations had the ability to inhibit their L1 neighbors and mitigate their influence. In the typing task, beginning about $700 \mathrm{msec}$ after picture onset, pictures with high-density neighborhood names elicited larger negativities than pictures with low-density neighborhood names. Such an effect is consistent with spreading of activation from L2 target words to their L1 neighbors within an integrated lexicon. Together, these results converge in suggesting that L1 orthographic neighborhood density in- fluences learning and processing of novel L2 words. Whereas the learning behavioral effects can potentially be attributed to strategic or articulatory processing, the effects on processing provide strong evidence for an integrated L1-L2 lexicon.

\section{Dense L1 Neighborhoods Scaffold Production of Novel Words}

By the end of training, participants achieved near-perfect accuracy in both tasks, suggesting that they had acquired the forms and meanings of the new words. As predicted, accuracy was higher for L2 words with many L1 orthographic neighbors in the typing task, but not in the 2AFC task. This demonstrates both the production advantage for novel words from high-density L1 neighborhoods and the null effect of L1 neighborhood density on recognition of novel words in the same group of learners 
Figure 7. Language decision: Difference waves. Difference waves created by subtracting the ERPs to L2 words in low-density L1 neighborhoods from the ERPs to L2 words in high-density L1 neighborhoods both before (black) and after (red) learning. Each vertical tick marks $100 \mathrm{msec}$, and negative is plotted up. The calibration bar marks $2 \mu \mathrm{V}$.

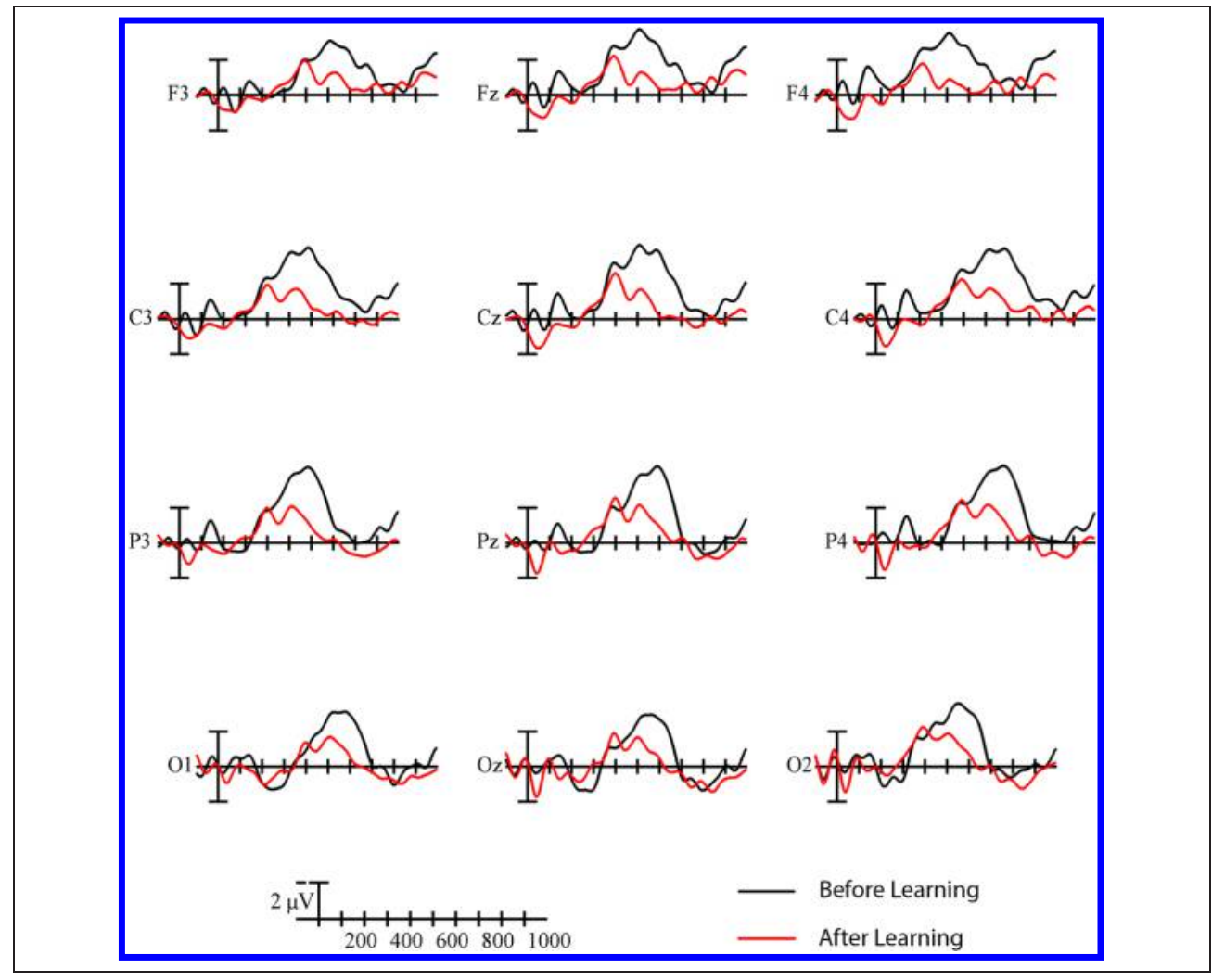

and in a study that is more representative of $\mathrm{L} 2$ learning. One explanation for the discrepancy between tasks is that orthographic neighborhood effects arise as a function of task difficulty. Accurate responses in the typing task required a precise form-level representation, whereas high accuracy in the 2AFC could be achieved with underspecified form representations, especially given that the L2 words were distinct from each other. It remains an open
Figure 8. Final typing task. (A) False discovery rate-corrected $p$ values at each time point and each electrode for the effect of neighborhood density in the typing task. Color indicates a significant effect. (B) Scalp voltage maps showing the effect of L1 neighborhood density (high-low) on picture processing (700-950 $\mathrm{msec}$ ). (C) Grand averaged ERP waveforms time-locked to picture onset at a representative set of central electrodes. Pictures with high-density names (solid) elicited a greater late negativity than pictures with low-density neighborhood names (dotted). Each vertical tick marks $100 \mathrm{msec}$, and negative is plotted up. The calibration bar marks $2 \mu \mathrm{V}$.

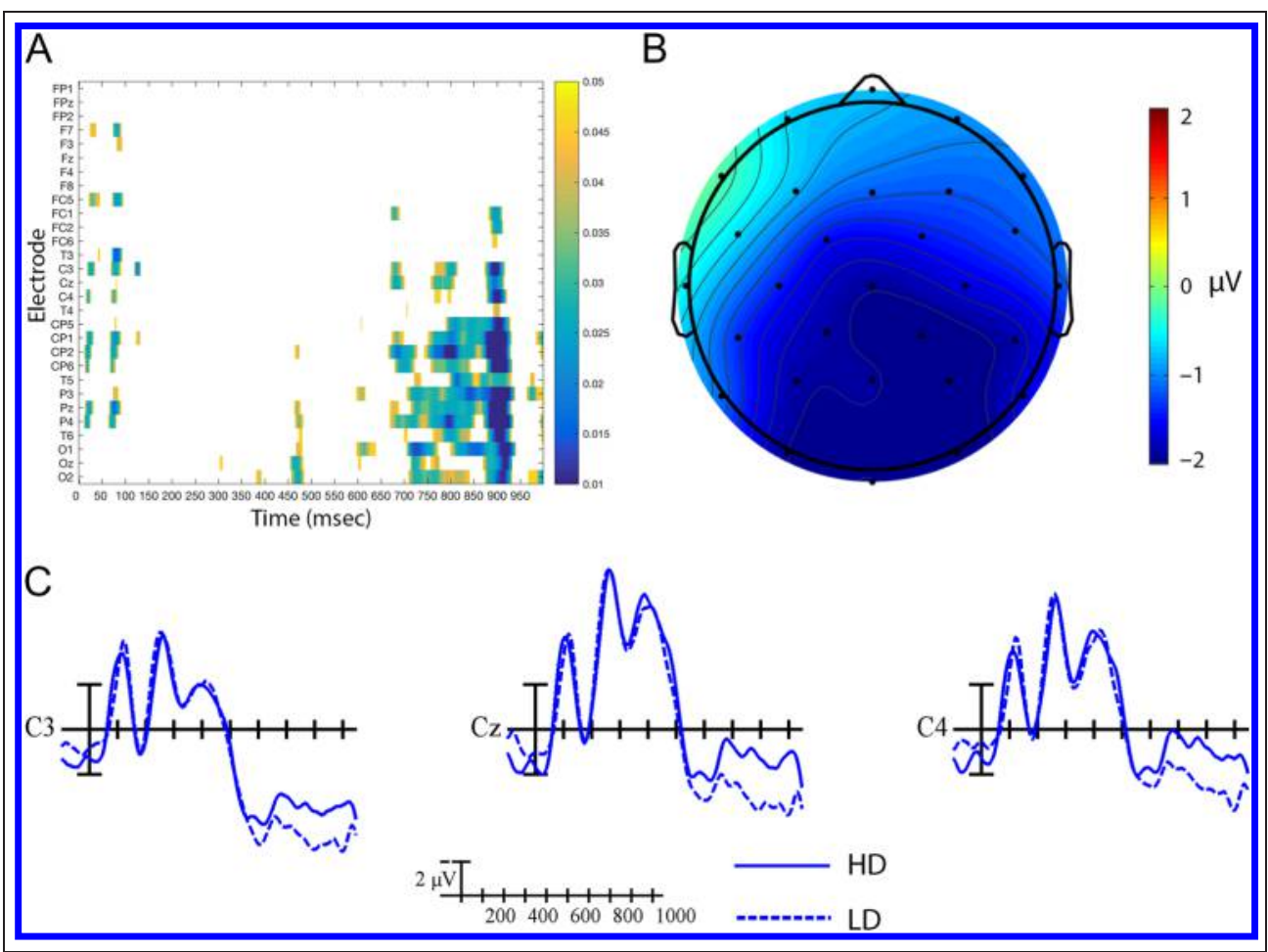


question whether a more difficult behavioral recognition task would engender effects of L1 orthographic neighborhood and, if so, whether these effects would be facilitatory or inhibitory.

The locus of the high-density orthographic neighborhood advantage that we found could theoretically originate at any stage of the production process. Facilitated production of existing words from high-density neighborhoods is thought to arise at the articulation stage (e.g., Carreiras et al., 1997), which may apply here as well. Another possibility, prompted by anecdotal participant reports, is that strategic associations between the novel L2 words and their L1 neighbors boosted learning. For example, one participant reported remembering the L2 word bink, associated with a picture of a pool, as a big sink. By definition, the availability of such form-similar keywords is higher for L2 words from high-density L1 neighborhoods than those from low-density L1 neighborhoods. This explanation would be consistent with studies demonstrating that explicitly presenting an L1 keyword during learning is particularly effective when the keyword overlaps in form with the novel L2 word (e.g., Ellis \& Beaton, 1993). Thus, the behavioral results over the course of learning suggest that L1 orthographic neighbors play a role in acquisition of L2 words but do not provide direct evidence of one lexical structure over the other.

\section{Effects of L1 Neighborhood Density Decrease with Learning}

Although recognition of L2 words was not significantly influenced by L1 orthographic neighborhood density in the behavioral 2AFC task, there was evidence from the language decision paradigm that L1 words were activated as the L2 words were processed. As predicted, we found ERP and behavioral effects of L1 orthographic neighborhood density before and after learning. L2 words with many L1 neighbors elicited greater negativities between 300 and $600 \mathrm{msec}$ and slower and less accurate responses than those with fewer L1 neighbors. Though this window extends beyond the N400 component itself and appears to affect the subsequent positivity, the difference waves suggest that it is one continuous effect. These results are consistent with cross-language effects reported in similar tasks in proficient bilinguals and interpreted to reflect an integrated lexicon (e.g., Dirix et al., 2017; Grossi et al., 2012; Midgley et al., 2008; Van Heuven et al., 1998). The greater negativity indexes the lexicosemantic processing of an increased number of L1 orthographic neighbors; the slower and less accurate language decisions reflect interference at the response level of these coactivated $\mathrm{L} 1$ representations.

These effects of L1 orthographic neighborhood for newly learned words are seemingly at odds with the null effects of L1 phonological neighborhood density in the visual world paradigm study reported by Magnuson et al. (2003). It seems unlikely that the discrepancy arose solely from the difference in modality (i.e., auditory vs. visual). A more theoretically interesting difference between the two studies is that associating the words with familiar meanings, as we did in this study, may have motivated lexicalization. When a familiar image is provided as a referent, the L1 word for that picture can be used as a memory aid (potentially further engaging the L1 lexicon during learning; see also Kaushanskaya, Yoo, \& Van Hecke, 2013), whereas no such anchor is available for the abstract geometric shapes used in the study by Magnuson and colleagues. Similarly, in a series of studies (Takashima, Bakker, van Hell, Janzen, \& McQueen, 2014, 2017), Takashima and colleagues have argued that lexicalization of novel words follows a gradient such that it is strongest for words associated with real objects, weaker for isolated words with no referent, and weakest for words with abstract referents. Thus, not only is learning L2 words with familiar meanings more representative of classroom L2 learning, it may have increased engagement of the L1 and engendered stronger effects of L1 neighborhood after learning.

It is also important to consider the influence of the tasks that were used in the two studies. There is little evidence to suggest that the eye-tracking paradigm used by Magnuson et al. (2003) is sensitive to neighborhood density. Although Magnuson (2001) found a weak effect of phonological neighborhood in a similar study with real English words, the English study included more items and the two neighborhood conditions were not controlled for the same nuisance variables as in the learning study (e.g., cohort density). Moreover, because their task depended on knowing the novel words, Magnuson and colleagues were unable to show that they were able to detect an effect of neighborhood before learning (i.e., when the novel words were presumably treated as pseudowords). Thus, it remains possible that the eye-tracking paradigm was simply not powerful enough to detect an effect of L1 neighborhood. In contrast, there is a clear precedent for behavioral and ERP effects of orthographic neighborhood in the LDT (e.g., Müller et al., 2010; Holcomb et al., 2002; Van Heuven et al., 1998; Carreiras et al., 1997; Grainger \& Jacobs, 1996), which extended to the language decision task used here. By using the same task both before and after learning, we were able to verify that our task was sensitive to coactivation of neighbors when the L2 words were unfamiliar pseudowords and examine how that coactivation changed after learning. Further investigations are needed to determine the specific factors that contribute to the strength of connections between new words and their existing phonological and orthographic neighbors. For now, our results in this pretest-posttest design strongly suggest that L1 neighbors are coactivated during processing of newly learned L2 words.

Evidence of cross-language orthographic neighborhood effects in a recognition task does not by itself provide conclusive evidence for an integrated lexicon in learners. Referring back to interactive activation models, it is feasible 
that bottom-up activation spreads from the letter level to words of both languages, without those words necessarily being stored together (see Kroll et al., 2010, for a similar argument). The greater negativity and delayed responses for words from high-density L1 orthographic neighborhoods only reliably indicate that $\mathrm{L} 1$ neighbors were coactivated, not that they were directly interacting with the representations of the novel $\mathrm{L} 2$ words.

Stronger support for an integrated lexicon comes from the evidence of a change in the effect of L1 orthographic neighbors as a function of learning. ERP and RT data converged in demonstrating that the influence of L1 orthographic neighborhood decreased with learning and that this change was due to more efficient processing of high-density neighborhood words after learning. This pattern is consistent with Holcomb et al.'s (2002) speculation that the larger effects of neighborhood for pseudowords as compared with existing words result from the inability of the system to settle on a single representation. Before learning, activation of the orthographic neighbors continues to resonate because no single representation matches the input. After learning, the newly formed L2 word representations can be selected and inhibit their L1 neighbors, thereby mitigating the effects of the latter. In a broader sense, this argument could also be framed in terms of frequency. The functional frequency of the L2 words increases from pretest to posttest, and there is evidence to suggest that within-language neighborhood effects are smaller for higher frequency words (e.g., Vergara-Martínez \& Swaab, 2012). That the change from pretest to posttest was specific to high-density orthographic neighborhood words supports these explanations over repetition or another uncontrolled factor that should have affected both types of L2 words similarly. These interactions are seemingly dependent on the L2 words being stored in the same lexicon as their L1 neighbors; if the lexicons were separate, but accessed in parallel, having a lexical representation of the L2 word should not influence the size of the effects of L1 orthographic neighborhood.

\section{Effects of L1 Neighborhood Density in a Production Task}

Perhaps the strongest evidence of an integrated lexicon comes from the finding that L2 words belonging to high-density L1 orthographic neighborhoods elicited a larger negativity in the typing task, even in the absence of a behavioral effect of neighborhood. These data are particularly compelling because the L2 word forms were never presented in this paradigm; participants were presented with pictures and had to produce the L2 words themselves. As a result, activation of orthographic neighbors cannot be attributed to bottom-up activation and must come from the learners accessing the L2 words as part of the production process.

This is, to our knowledge, the first report of an ERP effect of orthographic neighborhood structure in produc- tion. The effect has a posterior distribution consistent with the effects of frequency in the L1 picture typing task reported by Baus and colleagues (2013) but occurs some $350 \mathrm{msec}$ later. One explanation of this delay is that within-language effects of orthographic neighborhood are delayed relative to those of frequency in production, despite following a similar time course in recognition; another is that these newly learned L2 words were retrieved slower than L1 words. A similar study comparing brain activity during typing of L1 words with many versus few L1 orthographic neighbors would dissociate between these two alternatives. For now, given behavioral evidence of delayed L2 naming (see, e.g., Hanulová, Davidson, \& Indefrey, 2011, for a review), slower retrieval in the L2 seems to be the most plausible explanation.

This effect is nearly impossible to account for within the framework of functionally separate lexicons, especially given the remarkable control that is provided by a word learning experiment. For example, it is unlikely that the effect is due to semantics or to visual features of the pictures, because the pictures sets were counterbalanced across participants. Similarly, the two lists of words did not differ in L2 neighborhood density if we consider the 80 words learned as part of this experiment to be the L2 lexicon. It is thus difficult to imagine nuisance variables that might have contributed to this effect and equally difficult to explain how such an effect of L1 neighborhood could come about if lexicons were functionally separate.

\section{L1 or L2 Learning?}

Our decision to use pseudoword stimuli to have a wellcontrolled L1 neighborhood manipulation may elicit questions about the appropriate framework for interpreting these results. For example, learners in this study could have engaged the same strategy that they would normally use to learn new L1 items or L1 synonyms-in which case the effects reported here might not reflect true L2 word learning. We find this possibility unlikely, however, because of the safeguards built into our experimental design to assure an L2 learning context. First, and perhaps most important, we told participants that they were learning words from another language. This instruction set a specific learning context, which has been shown to be an important factor in numerous previous studies of L2 acquisition (see, e.g., Collentine \& Freed, 2004, for a review). Second, rather than an L1 LDT, which might have biased learners to treat the novel words as belonging to the $\mathrm{L} 1$, we had participants engage in a language decision task, which emphasizes the distinction between L1 and L2 words. And third, as mentioned above, we asked learners to associate the new words with pictures of familiar concepts that already had clear L1 labels. This type of explicit associative learning is very common in initial L2 classroom language learning (e.g., Webb, 2008), whereas adult L1 word learning more often occurs via 
passive implicit acquisition during reading and listening (e.g., Nation, 2001). Together, these elements of the experimental design should have encouraged learners to treat these new words as L2 words, rather than L1 synonyms.

The bigger and more important question this issue raises is whether learners at the initial stages of acquiring a rudimentary L2 vocabulary use the same or very similar neurocognitive mechanisms to those used when explicitly learning new words in their existing L1 or whether a completely different set of mechanisms is employed. We know of no direct empirical evidence that addresses this question, but future studies might compare groups taught the same novel words in clear L1 or L2 contexts. Regardless of the outcome of such studies, the implications of the current research seem clear. When adult learners think they are explicitly acquiring words in a new language, ERPs recorded in both recognition and production tasks to novel L2 words from low- and highdensity L1 orthographic neighborhoods favor the notion of an integrated L1-L2 lexicon. Specific form representations for L2 words with many L1 neighbors were acquired faster and had a greater influence on processing than those with only a few L1 neighbors. After learning, the L2 words coactivated and inhibited their L1 orthographic neighbors in a way that is reminiscent of within-language neighborhood effects and cross-language neighborhood effects in proficient bilinguals. These results seem to challenge a fundamental assumption in leading models of L2 processing in low-proficiency adult learners, namely that L1 and L2 words are stored in functionally separate lexicons (e.g., Grainger et al., 2010; Kroll \& Stewart, 1994) and suggest that L2 word learning may be more similar to L1 word learning in adults than previously thought.

\section{Acknowledgments}

This research was supported by grants from the National Institutes of Health (HD25889) and the National Science Foundation (BCS-1439257, GRFP 2016196208). We are grateful to James McQueen for valuable feedback on a previous version of the manuscript.

Reprint requests should be sent to Gabriela Meade, NeuroCognition Lab, San Diego State University Research Foundation, 6505 Alvarado Rd., Suite 203, San Diego, CA 92092, or via e-mail: meade.gabriela@gmail.com.

\section{Notes}

1. We assume a parsimonious lexical architecture in which both production and comprehension share a single orthographic lexical representation system (see also, e.g., Perfetti, 1992, p. 152) or are at least organized in a similar manner. Note, however, that there are accounts that suggest different input and output lexicons (e.g., Roelofs, 2003). In such a scenario, the interpretation of the typing results would be limited to the production lexicon. 2. A similar pattern emerged when Coltheart's $N$ (Coltheart et al., 1977) was used as the measure of neighborhood density. Low-density neighborhood L2 words (mean $=0.65, S D=0.89$ ) had significantly fewer neighbors on average than high-density neighborhood L2 words (mean $=8.05, S D=3.27$ ), $t(78)=$ $13.82, p<.001$. As in previous studies (e.g., Laszlo \& Federmeier, 2011), $N$ was correlated with the frequency of the neighbors, $r=$ $.58, p<.001$; thus, low-density neighborhood L2 words (mean $=$ $1.81, S D=6.58$ ) also tended to have less frequent neighbors than the high-density neighborhood L2 words (mean $=34.86$, $S D=35.9), t(78)=5.73, p<.001$, which may have contributed to the neighborhood effects that we report. Low-density neighborhood English words (mean $=0.75, S D=0.90$ ) also had significantly fewer neighbors on average than high-density neighborhood English words (mean $=7.40, S D=2.54), t(78)=16.61$, $p<.001$.

3. ERP data from an L2-L1 priming paradigm that was also conducted will not be reported here. Mean accuracies of $91 \%$ (range 84-100\%) for correct translations and 98\% (range 94$100 \%$ ) for incorrect translations on this task confirmed that participants were able to quickly access the novel words and map them to their English translation equivalents.

4. Using the same 100-msec prestimulus baseline as in the language decision task does not change the pattern of results in this later window, neighborhood, $F(1,19)=26.48, p<.001$, $\eta_{\mathrm{p}}^{2}=.58$.

\section{REFERENCES}

Andrews, S. (1997). The effect of orthographic similarity on lexical retrieval: Resolving neighborhood conflicts. Psychonomic Bulletin \& Review, 4, 439-461.

Bakker, I., Takashima, A., Van Hell, J. G., Janzen, G., \& McQueen, J. M. (2015). Changes in theta and beta oscillations as signatures of novel word consolidation. Iournal of Cognitive Neuroscience, 27, 1286-1297.

Barnhoon, J. S., Haasnoot, E., Bocanegra, B. R., \& van Steenbergen, H. (2015). QRTEngine: An easy solution for running online reaction time experiments using Qualtrics. Behavior Research Methods, 47, 918-929.

Bates, E., D’Amico, S., Jacobsen, T., Székely, A., Aandonova, E., Devescovi, A., et al. (2003). Timed picture naming in seven languages. Psvchonomic Bulletin E Review, 10, 344-380.

Baus, C., Strijkers, K., \& Costa, A. (2013). When does word frequency influence written production? Frontiers in Psychology, 4, 1-9.

Brysbaert, M., Warriner, A. B., \& Kuperman, V. (2014). Concreteness rating for 40 thousand generally known English word lemmas. Behavior Research Methods, 46, 904-911.

Carreiras, M., Perea, M., \& Grainger, J. (1997). Effects of orthographic neighborhood in visual word recognition: Cross-task comparisons. Journal of Experimental Psuchologv: Learning. Memorv and Cognition, 23, 857-871.

Casaponsa, A., Carreiras, M., \& Duñabeitia, J. A. (2014). Discriminating languages in bilingual contexts: The impact of orthographic markedness. Frontiers in Psychology, 5, $1-10$.

Collentine, J., \& Freed, B. F. (2004). Learning context and its effects on second language acquisition. Studies in Second Lanquage Acauisition, 26, 153-171.

Coltheart, M., Davelaar, E., Jonasson, J. T., \& Besner, D. (1977). Access to the internal lexicon. In S. Dornic (Ed.), Attention and performance IV (pp. 535-555). Hillsdale, NJ: Erlbaum

Dijkstra, T., Haga, F., Bijsterveld, A., \& Sprinkhuizen-Kuyper, I. (2012). Lexical competition in localist and distributed connectionist models of L2 acquisition. In J. Altarriba \& L. Isurin (Eds.), Memory, language, and bilingualism: Theoretical and applied approaches (pp. 48-73). Cambridge: Cambridge University Press. 
Dijkstra, T., Miwa, K., Brummelhuis, B., Sappelli, M., \& Baayen, H. (2010). How cross-language similarity and task demands affect cognate recognition. Journal of Memorv and Language. 62, 284-301.

Dijkstra, T., \& Van Heuven, W. J. B. (2002). The architecture of the bilingual word recognition system: From identification to decision. Bilingualism: Language and Cognition, 5, 175-197.

Dirix, N., Cop, U., Drieghe, D., \& Duyck, W. (2017). Cross-lingual neighborhood effects in lexical decision and natural reading. Lournal of Experimental Psychology: Learning. Memory. and Cognition, 43, 887-915.

Ellis, N. C., \& Beaton, A. (1993). Psycholinguistic determinants of foreign language vocabulary learning. Language Learning, 43, 559-617.

Ganushchak, L. Y., Christoffels, I. K., \& Schiller, N. O. (2011). The use of electroencephalography in language production research: A review. Frontiers in Psychology, 2, 1-6.

Gaskell, M. G., \& Dumay, N. (2003). Lexical competition and the acquisition of novel words. Cognition, 89, 105-132.

Grainger, J., \& Jacobs, A. M. (1996). Orthographic processing in visual word recognition: A multiple read-out model. Psuchological Review, 103, 518-565.

Grainger, J., Midgley, K., \& Holcomb, P. J. (2010). Re-thinking the bilingual interactive-activation model from a developmental perspective. In M. Kail \& M. Hickmann (Eds.), Language acquisition across linguistic and cognitive systems (pp. 267-283). Amsterdam: John Benjamins Publishing Company.

Grossi, G., Savill, N., Thomas, E. M., \& Thierry, G. (2012). Electrophysiological cross-language neighborhood density effects in late and early English-Welsh bilinguals. Frontiers in Psychology, 3, 1-11.

Hanulová, J., Davidson, D. J., \& Indefrey, P. (2011). Where does the delay in L2 picture naming come from? Psycholinguistic and neurocognitive evidence on second language word production. Language and Cognitive Processes, 26, 902-934.

Holcomb, P. J., Grainger, J., \& O'Rourke, T. (2002). An electrophysiological study of the effects of orthographic neighborhood size on printed word perception. Iournal of Cognitive Neuroscience, 14, 938-950.

Kaushanskaya, M., Yoo, J., \& Van Hecke, S. (2013). Word learning in adults with second-language experience: Effects of phonological and referent familiarity. Lournal of Speech. Language, and Hearing Research, 56, 667-678.

Kroll, J. F., \& Stewart, E. (1994). Category interference in translation and picture naming: Evidence for asymmetric connection between bilingual memory representations. Iournal of Memory and Language, 33, 149-174.

Kroll, J. F., Van Hell, J. G., Tokowicz, N., \& Green, D. W. (2010). The revised hierarchical model: A critical review and assessment. Bilingualism: Language and Cognition, 13, 373-381.

Kutas, M., \& Federmeier, K. D. (2000). Electrophysiology reveals semantic memory use in language comprehension. Trends in Cognitive Sciences, 4, 463-470.

Laszlo, S., \& Federmeier, K. D. (2009). A beautiful day in the neighborhood: An event-related potential study of lexical relationships in sentence context. Journal of Memory and Lanquage, 61, 326-338.

Laszlo, S., \& Federmeier, K. D. (2011). The N400 as a snapshot of interactive processing: Evidence from regression analyses of orthographic neighbor and lexical associate effects. Psychopbysiology, 48, 176-186.

Lau, E. F., Phillips, C., \& Poeppel, D. (2008). A cortical network for semantics: [De]constructing the N400. Nature Reviews Neuroscience, 9, 920-933.
Magnuson, J. S. (2001). The microstructure of spoken word recognition. (Unpublished doctoral dissertation), University of Rochester, Rochester, NY.

Magnuson, J. S., Tanenhaus, M. K., Aslin, R. N., \& Dahan, D. (2003). The time course of spoken word learning and recognition: Studies with artifical lexicons. Iournal of Experimental Psychology: General, 132, 202-227.

McClelland, J. L., \& Rumelhart, D. E. (1981). An interactive activation model of context effects in letter perception: I. An account of basic findings. Psychological Review, 88, 375-407.

McLaughlin, J., Osterhout, L., \& Kim, A. (2004). Neural correlates of second-language word learning: Minimal instruction produces rapid change. Nature Neuroscience, 7, 703-704.

Medler, D. A., \& Binder, J. R. (2005). MCWord: An on-line orthographic database of the English language. Retrieved from http://www.neuro.mcw.edu/mcword.

Midgley, K. J., Holcomb, P. J., \& Grainger, J. (2009). Language effects in second language learners and proficient bilinguals investigated with event-related potentials. Journal of Neurolinguistics, 22, 281-300.

Midgley, K. J., Holcomb, P. J., Van Heuven, W. J. B., \& Grainger, J. (2008). An electrophysiological investigation of cross-language effects of orthographic neighborhood. Brain Research, 1246, $132-135$

Müller, O., Duñabeitia, J. A., \& Carreiras, M. (2010). Orthographic and associative neighborhood density effects: What is shared, what is different? Psychopbysiology 47, 455-466.

Nation, I. S. P. (2001). Learning vocabulary in another language. New York: Cambridge University Press.

Perfetti, C. A. (1992). The representation problem in reading acquisition. In P. B. Gough, L. C. Ehri, \& R. Treiman (Eds.), Reading acquisition (pp. 145-174). Hillsdale, NJ: Erlbaum.

$\mathrm{Pu}$, H., Holcomb, P. J., \& Midgley, K. (2016). Neural changes underlying early stages of L2 vocabulary acquisition. Journal of Neurolinguistics, 40, 55-65.

Rastle, K., Harrington, J., \& Coltheart, M. (2002). 358,534 Nonwords: The ARC Nonword Database. The Quarterly Journal of Experimental Psychology, Section A, Human Experimental Psvchology, 55, 1339-1362.

Roelofs, A. (2003). Modeling the relation between production and recognition of spoken word forms. In N. O. Schiller \& A. S. Meyer (Eds.), Phonetics and phonology in language comprebension and production: Differences and similarities (pp. 115-158). Berlin, Germany: Mouton de Gruyter.

Spivey, M. J., \& Marian, V. (1999). Cross talk between native and second languages: Partial activation of an irrelevant lexicon. Psychological Science, 10, 281-284.

Storkel, H. L., Armbrüster, J., \& Hogan, T. P. (2006). Differentiating phonotactic probability and neighborhood density in adult word learning. Iournal of Speech. Language. and Hearing Research, 49, 1175-1192.

Takashima, A., Bakker, I., van Hell, J. G., Janzen, G., \& McQueen, J. M. (2014). Richness of information about novel words influences how episodic and semantic memory networks interact during lexicalization. Neuroimage, 84, 265-278.

Takashima, A., Bakker, I., van Hell, J. G., Janzen, G., \& McQueen, J. M. (2017). Interaction between episodic and semantic memory networks in the acquisition and consolidation of novel spoken words. Brain and Language, 167, 44-60

Vaid, J., \& Frenck-Mestre, C. (2002). Do orthographic cues aid language recognition? A laterality study with French-English bilinguals. Brain and Language, 82, 47-53.

Van Heuven, W. J. B., Dijkstra, T., \& Grainger, J. (1998). Orthographic neighborhood effects in bilingual word recognition. Journal of Memorv and Lanquage, 39, 458-483. 
Vergara-Martínez, M., \& Swaab, T. (2012). Orthographic neighborhood effects as a function of word frequency: An event-related potential study. Psvchophvsiologv, 49, 1277-1289.

Vitevitch, M. S. (2002). The influence of phonological similarity neighborhoods on speech production. Lournal of

Experimental Psychology: Learning. Memorv. and Cognition, 28, 735-747.

Vitevitch, M. S. (2012). What do foreign neighbors say about the mental lexicon? Bilingualism: Language and Cognition, 15, $167-172$.
Vitevitch, M. S., Luce, P. A., Pisoni, D. B., \& Auer, E. T. (1999). Phonotactics, neighborhood activation, and lexical access for spoken words. Brain and Language, 68, 306-311.

Webb, S. (2008). Receptive and productive vocabulary sizes of L2 learners. Studies in Second Lanquage Acquisition, 30, 79-95.

Yarkoni, T., Balota, D. A., \& Yap, M. J. (2008). Moving beyond Coltheart's $N$ : A new measure of orthographic similarity. Psychonomic Bulletin \& Review, 15, 971-979. 


\section{This article has been cited by:}

1. Gabriela Meade. 2019. The role of phonology during visual word learning in adults: An integrative review. Psychonomic Bulletin \& Review 139. . [Crossref]

2. Mathieu Declerck. 2019. What about proactive language control?. Psychonomic Bulletin \& Review 33. . [Crossref]

3. Gabriela Meade, Jonathan Grainger, Phillip J. Holcomb. 2019. Task modulates ERP effects of orthographic neighborhood for pseudowords but not words. Neuropsychologia 129, 385-396. [Crossref]

4. Angela Grant, Jennifer Legault, Ping Li. What Do Bilingual Models Tell Us About the Neurocognition of Multiple Languages? 48-74. [Crossref]

5. Gabriela Meade, Katherine J. Midgley, Phillip J. Holcomb. 2018. An ERP Investigation of L2-L1 Translation Priming in Adult Learners. Frontiers in Psychology 9. . [Crossref]

6. Gabriela Meade, Jonathan Grainger, Katherine J. Midgley, Karen Emmorey, Phillip J. Holcomb. 2018. From sublexical facilitation to lexical competition: ERP effects of masked neighbor priming. Brain Research 1685, 29-41. [Crossref]

7. Gabriela Meade, Ton Dijkstra. Mechanisms underlying word learning in second language acquisition 49-72. [Crossref] 